\title{
Doença de Behçet com Extensa Trombose Venosa
}

\section{Behçet Disease with Vast Venous Thrombosis}

\author{
Varlei Antonio Serratto ${ }^{(1)}$, Juliana Gomes Loyola Netto ${ }^{(2)}$, Lysandra Yoshizumi ${ }^{(3)}$, Eduardo Paiva ${ }^{(4)}$
}

\section{RESUMO}

A doença de Behçet é uma entidade clínica rara que pode acometer o sistema vascular, levando à trombose de grandes vasos. Os autores descrevem um caso de trombose extensa, em um paciente jovem, como manifestação desta doença.

Palavras-chave: doença de Behçet, trombose, átrios do coração.

\section{INTRODUÇÃO}

A doença de Behçet (DB) é um distúrbio multissistêmico caracterizado como vasculite, com diagnóstico clínico baseado, principalmente, na presença de úlceras orais recorrentes, que podem se associar a úlceras genitais, manifestações oculares e cutâneas, além do envolvimento de vários órgãos, incluindo intestinos, coração, sistema nervoso central (SNC), pulmões e sistema vascular. Neste último, tanto as artérias como as veias podem ser acometidas com o desenvolvimento de eventos trombóticos ${ }^{(1,2,3)}$.

A trombofilia na DB ainda não tem esclarecido seus mecanismos fisiopatogênicos. Neste artigo, será relatado um paciente com $\mathrm{DB}$, que apresentou trombose extensa de veia cava inferior, veia intra-hepática, que evoluiu até o átrio direito e a subclávia esquerda ${ }^{(1,2,3)}$.

\section{RELATO DE CASO}

Paciente masculino, 16 anos, que uma semana antes da internação, iniciou com dispnéia súbita, aos pequenos esforços e, posteriormente, ao repouso. Negava ortopnéia, dispnéia paroxística noturna, sem edemas, sem dor torácica, hemoptise, tosse ou febre.

Apresentava dor em membros inferiores, diminuição da acuidade visual de olho direito e dor em olho esquerdo. Úlceras escrotais estavam presentes, mas o paciente

\begin{abstract}
Behçet disease is a rare disorder that may affect the vascular system and promote large-vessels thrombosis. The authors describe a rare case of vast thrombosis in a young patient as a manifestation of this disease.
\end{abstract}

Keywords: Behçet disease, thrombosis, heart atria.

negava úlceras orais recentes. Ao exame físico, apresentava taquipnéia, cianose central dependente de $\mathrm{O}_{2}$ a $2 \mathrm{l} / \mathrm{min}$ para melhora dos sintomas, olhos vermelhos, exame pulmonar e cardíaco sem particularidades, abdome com discreta dor à palpação de hipocôndrio direito com circulação colateral de tórax ascendente mais desenvolvida em lado direito, úlceras escrotais de 2 a $3 \mathrm{~cm}$ de diâmetro dolorosas sem secreção e ausências de cacifo em membros inferiores.

O paciente fazia o acompanhamento no Serviço de Dermatologia e Oftalmologia por DB há três anos com úlceras orais e escrotais associadas à uveíte anterior bilateral, com vasculopatia oclusiva periférica, atrofia de fóvea e retinopatia isquêmica em ambos os olhos e acuidade visual relativamente boa.

A saturação de $\mathrm{O}_{2}$ a $21 /$ min era de $96,6 \%, \mathrm{PO}_{2}$ de 58,8 $\mathrm{mmHg}, \mathrm{PCO}_{2}$ de 25,6 mmHg e $\mathrm{Ph} 7,33$; raio-x de tórax com discreto abaulamento de arco pulmonar; eletrocardiograma (ECG) normal; velocidade de hemossedimentação (VHS) de $65 \mathrm{~mm}$ na primeira hora; hemoculturas negativas. $\mathrm{Na}$ evolução, precisou ser aumentado $\mathrm{O}_{2}$ para $5 \mathrm{l} / \mathrm{min}$ para melhora da dispnéia e da saturação de $\mathrm{O}_{2}$. Iniciou-se heparinização plena e corticosteróide na dose de $1 \mathrm{mg} / \mathrm{kg} /$ dia.

A tomografia de tórax (Figura 1) mostrava derrame pleural bilateral, atelectasia parcial em lobo inferior direito, trombose de segmento intra-hepático de veia cava inferior com dilatação de veias ázigos e hemiázigos, presença de veia cava persistente, drenando para veia hemiázigos através de

Trabalho realizado no Serviço de Reumatologia do Departamento de Clínica Médica do Hospital de Clínicas da Universidade Federal do Paraná (UFPR). Recebido em 18/11/2004. Aprovado, após revisão, em 28/07/06.

1. Especializando em Reumatologia do Hospital de Clínicas da UFPR.

2. Residente em Dermatopediatria do Hospital de Clínicas da UFPR.

3. Residente em Clínica Médica do Hospital de Clínicas da UFPR.

4. Médico Reumatologista do Hospital de Clínicas da UFPR

Endereço para correspondência: Varlei Antonio Serratto, Disciplina de Reumatologia, Departamento de Clínica Médica do Hospital de Clínicas da UFPR, Rua Edmundo Filla, 18, CEP 81200-260, Curitiba, PR, Brasil, telefone: (41) 373-4573, e-mail: varleiserratto@hotmail.com 
arco hemiázigos acessório (variante anatômico). Trombose em veia subclávia esquerda, continuando-se para topografia de mediastino posterior na região do ducto torácico.

Ecografia de abdome total mostrava hepatomegalia homogênea, trombose total de veia cava inferior ao nível hepático e de ilíaca comum à esquerda, trombose parcial de veia cava inferior da junção das ilíacas comuns até nível hepático e veia supra-hepática direita. Também observou-se trombose ao nível das junções das ilíacas comuns até átrio direito com discreto fluxo na porção inferior (Figura 2).

O paciente evoluiu com dispnéia até $9^{\circ}$ dia de internação, necessitando de oxigenoterapia contínua a $5 \mathrm{l} / \mathrm{min}$. No $10^{\circ}$ dia, não houve mais a necessidade de $\mathrm{O}_{2}$, o paciente começou a deambular normalmente, com desaparecimento da circulação colateral em tórax à direita. No $13^{\circ}$ dia, não houve outras intercorrências e o paciente recebeu alta com anticoagulação efetiva com femprocumona, assintomático, com melhora das úlceras genitais, sem dor ocular e acuidade visual mantida. Medicado com prednisona $1 \mathrm{mg} / \mathrm{kg} /$ dia e azatioprina 1 $\mathrm{mg} / \mathrm{kg} /$ dia sendo encaminhado ao ambulatório e a pesquisa de anticorpos antifosfolipídios resultou negativa.

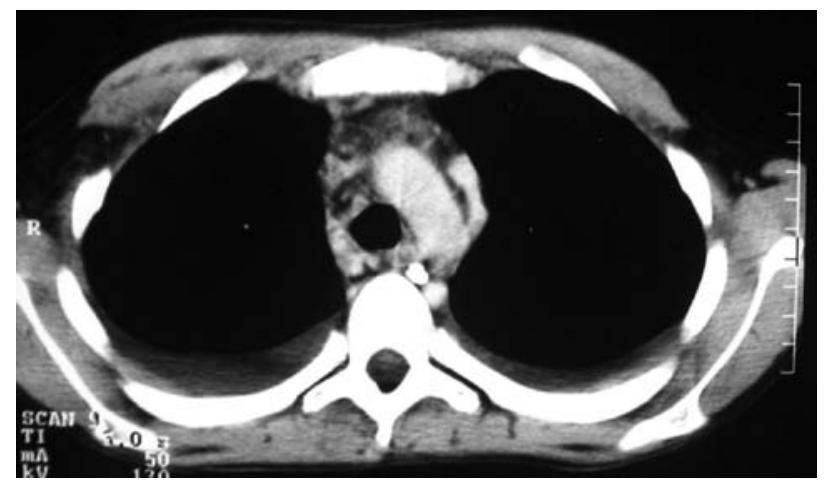

Figura 1 - Derrame pleural bilateral.

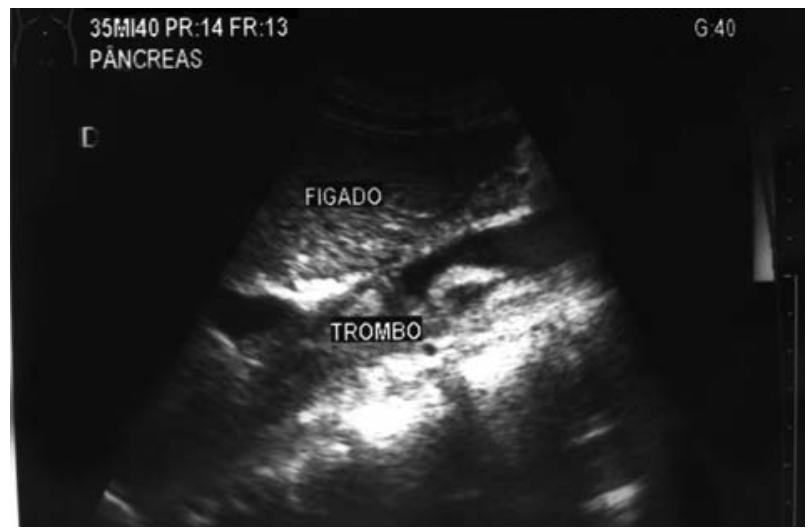

Figura 2 - Trombose em veia cava inferior em nível hepático.

\section{DISCUSSÃO}

A doença de Behçet, sabidamente, é uma doença trombofílica. Há vários relatos na literatura de fenômenos trombóticos nesta doença, tanto arteriais como venosos (7\% arteriais, $25 \%$ venosos e $68 \%$ arteriais/venosos) $)^{(2)}$, de vasos pequenos aos de grande calibre, nos mais variados locais, principalmente na veia cava inferior.

O mecanismo de trombose na DB é ainda desconhecido e várias causas foram propostas. A presença de anticorpos antifosfolípides tem sido relatada, mas não está clara a sua associação com a DB ${ }^{(4,2)}$. A presença de anticorpos anticélulas endoteliais explica alguns fenômenos vasculares, mas não é específica para doença intracardíaca e alguns acreditam que existam anticorpos contra antígenos de células endocárdicas ${ }^{(4)}$. Há também relatos de aumento dos níveis de fator Von Willebrand e aumento da inibição do ativador de plasminogênio tecidual $^{(4)}$. Há resistência na ativação da proteína $\mathrm{C}$ e elevados níveis de homocisteína ${ }^{(5,6,7)}$ e mutações no fator $\mathrm{V}$ de Leiden são também encontrados. Todas as pessoas que possuem o fator $\mathrm{V}$ de Leiden mostram resistência à ativação de proteína $\mathrm{C}$ e cerca de $15 \%$ dos casos de resistência à proteína $\mathrm{C}$ não ocorre mutação no fator V de Leiden ${ }^{(8)}$. Em 1998, Oner et $a^{(9)}$ demonstraram que a presença da mutação do fator $\mathrm{V}$ de Leiden é mais comum na $\mathrm{DB}^{(10,11,12)}$.

Sabe-se que, mesmo em controles adequados de anticoagulação, o paciente com DB faz novas tromboses, o que sugere outros mecanismos ainda não esclarecidos ${ }^{(13)}$.

A trombose é mais comum em homens jovens, com idade variando entre a segunda e a terceira décadas de vida, com diagnóstico de DB de 3,2 a 5,8 anos ${ }^{(1,14)}$. Em homens, a trombose tem predomínio de 4 a 18 vezes maior do que em mulheres $^{(15,1)}$. Os fatores de risco para trombose de grandes vasos, como os que ocorrem em veia intra-hepático, são as tromboflebites superficiais e trombose de veia cava inferior, e sua apresentação é infrequente, cerca de 5\%, na ausência destes fatores de risco ${ }^{(15,1)}$. Apesar de alguns autores terem encontrado uma freqüência aumentada de alguns fatores de risco para trombose na $\mathrm{DB}, \mathrm{o}$ mecanismo desta ainda não está esclarecido.

Outro relato mostra que a tromboflebite superficial precede a trombose profunda de cava e $\operatorname{arterial}^{(3)}$.

Outra série descreve que a trombose intra-cardíaca ocorre em 1 a $7 \%$ dos pacientes, mais comumente em câmaras direitas e dentre elas em átrio direito ${ }^{(16)}$. A presença de anticorpos antifosfolípides foi identificada como fator de risco para a trombose. Os pacientes possuíam níveis de proteína C e S normais neste estudo. 
O envolvimento cardíaco é mais comum em homens jovens com doença sistêmica grave ${ }^{(4)}$. Há autores que defendem que o envolvimento de câmaras direitas, além de raro, ocorre mais associado à vasculite pulmonar. $\mathrm{O}$ manejo terapêutico fica dependente do comprometimento hemodinâmico e sinais de insuficiência cardíaca, com tendência ao tratamento conservador, podendo ser cirúrgico quando não-responsivo ou indicado por outro motivo, como a localização do trombo no septo ou livre, por exemplo ${ }^{(3)}$.

É descrita uma síndrome ${ }^{(13)}$, chamada Stovim-Hughes, em que ocorre trombose venosa profunda ou trombose de cava inferior e superior associada a múltiplos aneurismas arteriais.

Compreende-se, então, que o envolvimento vascular (vásculo-Behçet) é o maior determinante do prognóstico da $\mathrm{DB}^{(3)}$.

\section{REFERÊNCIAS}

1. Kock Y, Gullu I, Akpek G, et al: Vascular involvement in Behçet`s disease. J Rheumatol 19: 402-10, 1992.

2. Tunaci A, Brkmen YM, Gokm NE: Thoracic involvement in Behçet`s disease: pathologic, clinical, and imaging features. AJR 164: 51-6, 1995.

3. http://www.arthritis.org/research/Bulletin/Vol53No/ Printable.htm- 19/5/2004.

4. Mogulkoc N, Burger MI, Bishop PW: Intracardiac Thrombus in Behçet's disease. Chest 118:479-87, 2000.

5. Canataroglu A, Tanriverdi K, Inal T, et al: Methylenetetrahydrofolate reductase gene C677T mutation and plasma homocysteine level in Behcet's disease. Rheumatol Int 23: 236-40, 2003.

6. Houman H, Fekim, Grobel IB, et al: Does hyperhomocysteinemia increase the risk of thrombosis in Behçet's disease? Adv Exp Med Biol 528: 413-7, 2003.

7. Calikoglu E, Oztas M, Sengul N, Adam B, Gurer MA: S Serum homocysteine level in Behcet's disease. Haematologia 32: 219-24, 2002 .

8. Koskmaz C, Bozan B, Kosar M, et al: Is there an association of
Neste nosso relato observa-se que os dados epidemiológicos (idade, sexo, tempo de doença) são congruentes com a literatura para as manifestações de trombose que o paciente apresentou. A pesquisa para a síndrome antifosfolípide foi negativa e não foi pesquisado algum outro distúrbio de coagulação que pudesse estar associado à doença. O caso torna-se ímpar pela extensão e locais de trombose apresentada (átrio direito, veia intra-hepática, veia subclávia esquerda), pela idade jovem do paciente e a gravidade do prognóstico, visto que novos fenômenos trombóticos podem ocorrer, mesmo com a terapêutica adequada de anticoagulação e controle da doença.

Declaramos a inexistência de conflitos de interesse. plasma homocysteine levels with vascular involvement in patients with Behçet`s disease? Clin Exp Rheumatol 20 (4 supp 126): 5304, 2002.

9. Oner AF, Gurgey A, Gurler A, Mesci L: Factor V Leiden mutation in patients with Behçet`s disease. J Rheumatol 25: 496-8, 1998.

10. Gul A, Ozbek V, Ozbek C, et al: Coagulation factor V Leiden gene mutation increase the risk of venous thrombosis in Behçet's disease. British J Rheumatol 35: 1178-80, 1996.

11. Svensson PJ, Dahkback B: Resistence to activated protein C as a basis for venous thrombosis. NEJM 330: 517-22, 1994.

12. Deguiero F, Tosetto A: Activated protein $\mathrm{C}$ resistence and factor $\mathrm{V}$ Leiden mutation are independent risk factors of venous thromboembolism. An Int Med 130: 643-50, 1999.

13. Sanchez-Burson J, Corzo JE, Marenco JL, Rejon-Gieb E: Thrombolytic therapy in pulmonary embolism of Behçet's disease. Acta haematol 96: 181-3, 1996.

14. Ko GY, Byum JY, Choi BG, Cho SH: The vascular manifestations of Behçet's disease: angiographic and CT findings. Br J Radiol 73: 1270-4, 2000.

15. Bismuth E, Handegue A, Hammel P, Benhamou JP: Hepatic vein thrombosis in Behçet's disease. Hepatology 11: 969-74, 1990. 